\title{
Increased wear and oxidation resistance of titanium aluminide alloys by laser cladding
}

\author{
Sörn Ocylok ${ }^{1, a}$, Andreas Weisheit ${ }^{1, b}$ Ingomar Kelbassa ${ }^{2, c}$ \\ ${ }^{1}$ Fraunhofer Institute for Laser Technology, Steinbachstraße 15, 52074 Aachen, Germany \\ ${ }^{2}$ Chair for Laser Technology, RWTH Aachen University, Steinbachstraße 15, \\ 52074 Aachen, Germany \\ asoern.ocylok@ilt.fraunhofer.de, bandreas.weisheit@ilt.fraunhofer.de, \\ cingomar.kelbassa@ilt.fraunhofer.de
}

Key words: Laser cladding, titanium aluminide, wear resistance, oxidation resistance

\begin{abstract}
A process layout for laser cladding of layers on substrates of titanium aluminides using state-of-theart and modified (additions of $\mathrm{Si}$ and $\mathrm{TiB}_{2}$ ) TiAl alloys is presented. The process involves a preheating of the samples to reduce thermal stresses and cladding in an inert gas atmosphere with an oxygen content lower than $30 \mathrm{ppm}$. These conditions lead to crack free layers and low surface oxidation. Microstructure and hardness of the layers are investigated. The abrasive wear resistance of the cladded layers in comparison to the base material is tested with promising results. Finally results of the oxidation behavior are shown and prove the increased performance of modified TiAl layers in comparison to the base material.
\end{abstract}

\section{Introduction}

One major demand of the aircraft industry is to increase the thrust-to-weight-ratio of engines. The choice of material for the low pressure turbine blades and the high pressure compressor blades is one key factor to decrease the weight of the engine. Gamma titanium aluminide alloys have a high potential to decrease the engine weight due to their low density in comparison to nickel-based superalloys [1]. Gamma-TiAl materials are suitable for applications in aircraft engines because of their good oxidation resistance at temperatures up to 700 degrees Celsius in combination with excellent mechanical properties [2].

Turbine blades made of TiAl will be in operation in the near future [3]. The main challenge then will be the repair of such valuable parts as well as the improved wear and corrosion resistance to prolong the lifetime. Laser cladding represents an established process in the aircraft industry to repair turbine parts. However, experience with intermetallics is low [4] and such brittle materials with a breaking elongation lower than $2.0 \%$ at room temperature [5] require special conditions like preheating up to temperatures of 1000 degrees Celsius.

\section{Laser cladding process}

Laser cladding is a powder-based process to increase wear, corrosion and oxidation resistance of parts by a near net shape cladding with adapted materials [6]. The powder can be fed either offaxially or coaxially [7]. Figure 1a shows a discontinuous coaxial powder feed nozzle used for the experiments. The powder material is fed by three individual powder gas streams to the interaction zone in a carrier gas stream (helium or argon). The laser beam melts the powder material particles and a small zone of the base material (fig. 1b). After solidification a layer with a metallurgical bonding to the substrate is produced. By adaptation of the process parameters such as velocity, powder feed rate and laser power, the thickness of the built layer can be varied typically from 0.1 up to $3 \mathrm{~mm}$ in a single pass. The main advantages of the laser cladding process are high precision, a minimized heat affected zone (HAZ), low distortion and the variety of materials. Nearly every metallic material can be cladded. Single crystal nickel based superalloys can be used as well as intermetallics (e.g. titanium aluminide) and high-melting point metals such as tungsten. 

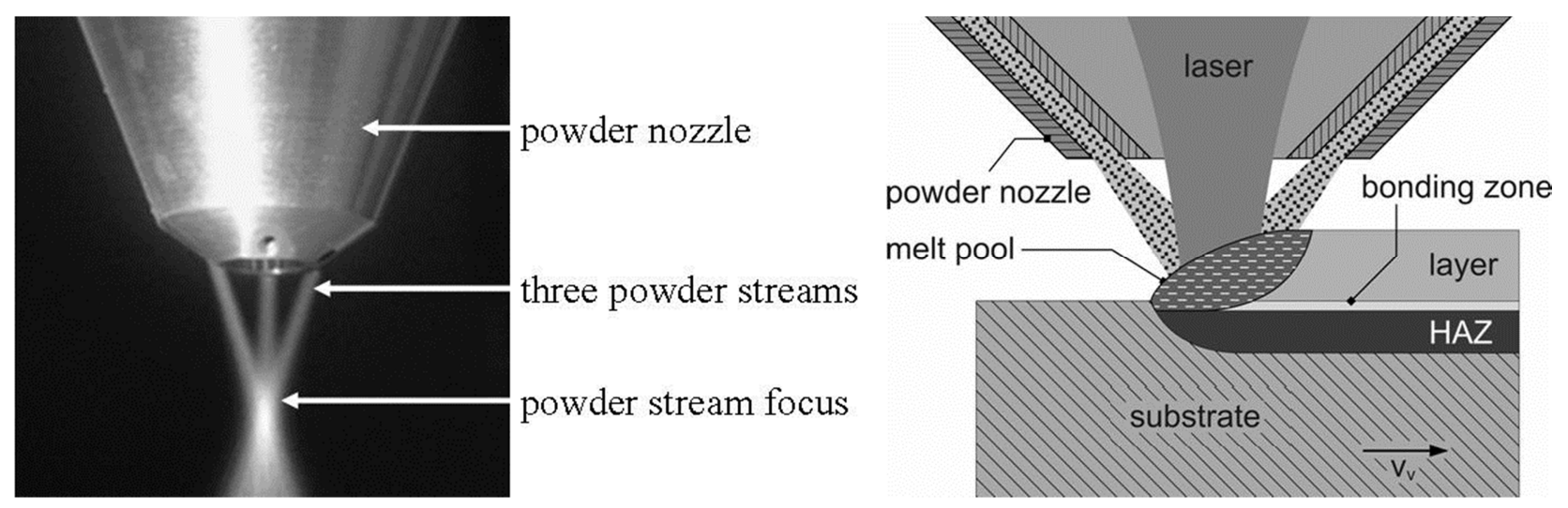

Figure 1: a: Discontinuous coaxial-powder feeding; b: Principle of the laser cladding process

\title{
Equipment and materials
}

Experiments are carried out using a 5-axis handling system equipped with a $2 \mathrm{~kW}$ fiber-coupled diode laser. A preheating unit for temperatures up to 1000 degrees Celsius made of four single resistive heating elements is used in combination with a shielding gas chamber to avoid oxidation of the sample (fig. 2). Cladding experiments are conducted with a focus diameter of $2.0 \mathrm{~mm}$ and an overlap of single tracks of $1.0 \mathrm{~mm}$. The powder is fed by a twin powder feeder utilizing a volumetric method of feed rate control by a grooved rotating disc to deliver a precise quantity of powder. Helium is used as carrier gas for the feeding of the powder into the interaction zone and also as shielding gas in the chamber to minimize oxidation during preheating, cladding and cooling.

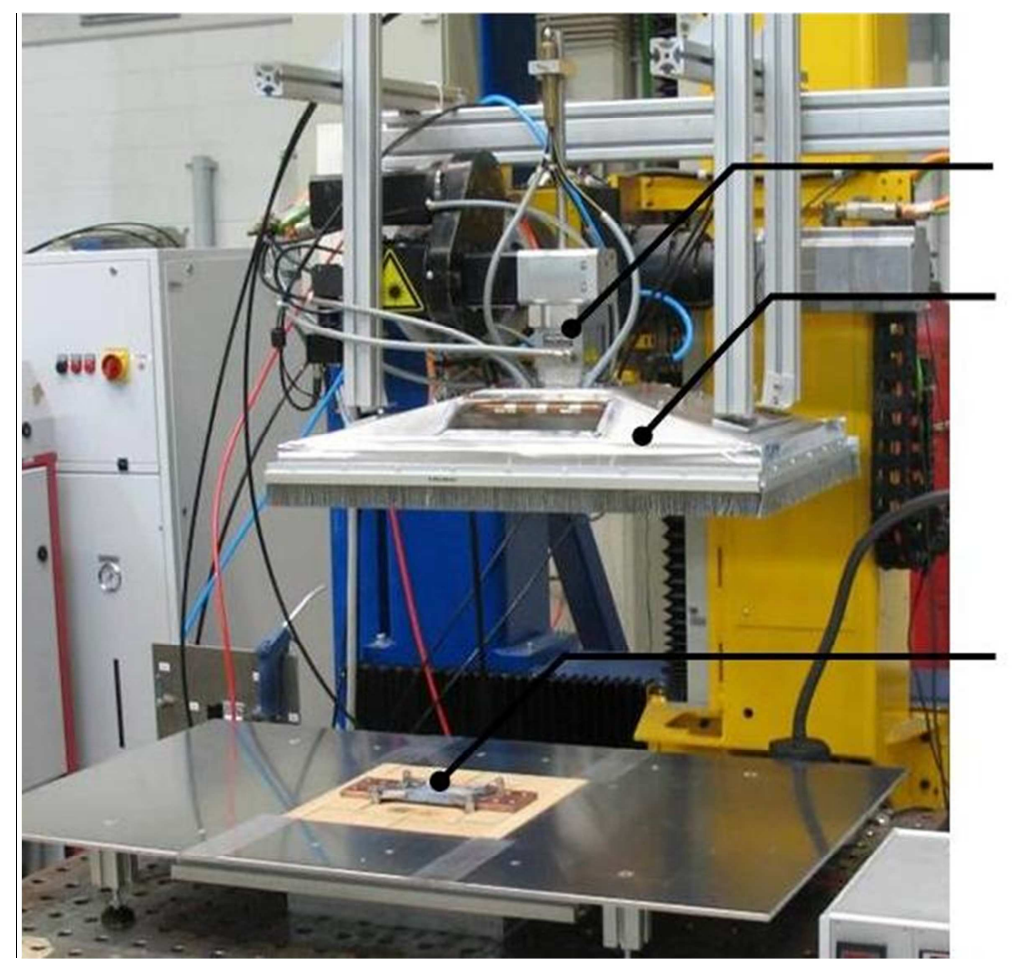

processing head with optics

\author{
shielding gas shroud
}

preheating unit

Figure 2: Handling system with preheating unit shielding gas chamber

For laser cladding a TiAl alloy (see table 1) is mixed with various contents of silicon and titanium diboride either prior to cladding $(\mathrm{Si})$ or during the process $\left(\mathrm{TiB}_{2}\right)$. Plates of Ti-46.8Al-1Cr-0.2Si are used as substrate (thickness $6 \mathrm{~mm}$ ). 
Table 1: Base material and powders materials

\begin{tabular}{|l|l|l|l|}
\hline Powder material & $\begin{array}{l}\text { Additional powder } \\
\text { material }\end{array}$ & $\begin{array}{l}\text { Contents of additional } \\
\text { materials }\end{array}$ & Substrate material \\
\hline Ti-46.8Al-1Cr-0.2Si & $\mathrm{Si}$ & $0.5,1,5,10,15 \mathrm{wt} .-\%$ & Ti-46.8Al-1Cr-0.2Si \\
\hline Ti-46.8Al-1Cr-0.2Si & $\mathrm{TiB}_{2}$ & $20-75 \mathrm{wt} .-\%$ & Ti-46.8Al-1Cr-0.2Si \\
\hline
\end{tabular}

To evaluate the wear resistance a simple abrasive blasting test is used. The principle of the test is shown in fig. 3. A stream of sharp-edged aluminum oxide powder, with an average grain size of $110 \mu \mathrm{m}$ is blasted with 3 bar air-pressure under a certain angle (10 degrees) onto the surface of the sample for a time of 180 seconds. The weight of the samples is measured before and after the test and used a measure for the abrasive wear.

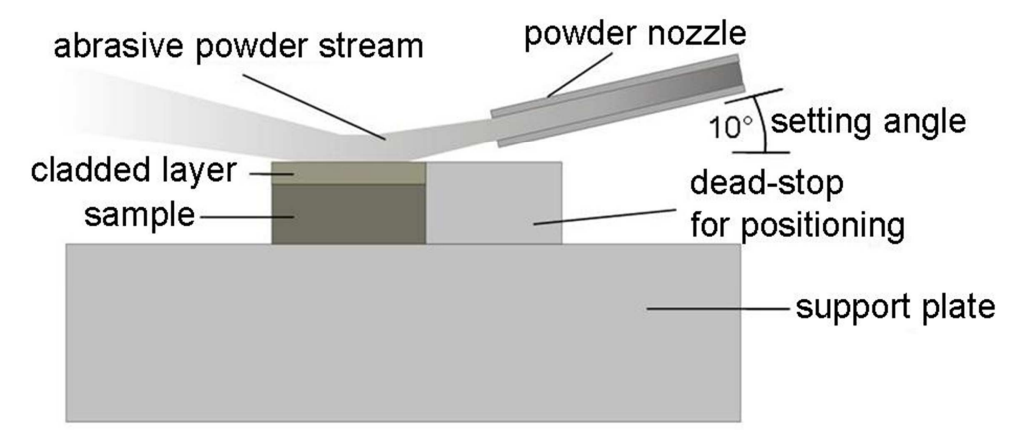

Figure 3: Schematic principle of the abrasive wear resistance test

\section{Preheating and cooling}

Experiments are carried out with a preheating temperature of 900 degrees Celsius of the substrate and a helium atmosphere with approx. 30ppm oxygen content underneath the shielding gas shroud. The cycle of preheating, holding and slow cooling is shown in fig. 4. Heating can be done rather fast. Before cladding 5 min holding time are needed to ensure a homogeneous temperature of the sample. Cladding is followed again by $5 \mathrm{~min}$ holding. Then the cooling starts with a cooling rate of $6 \mathrm{~K} / \mathrm{min}$ which is required to avoid cracking due to thermal stresses. When a temperature of 200 degrees Celsius is achieved cooling can be faster.

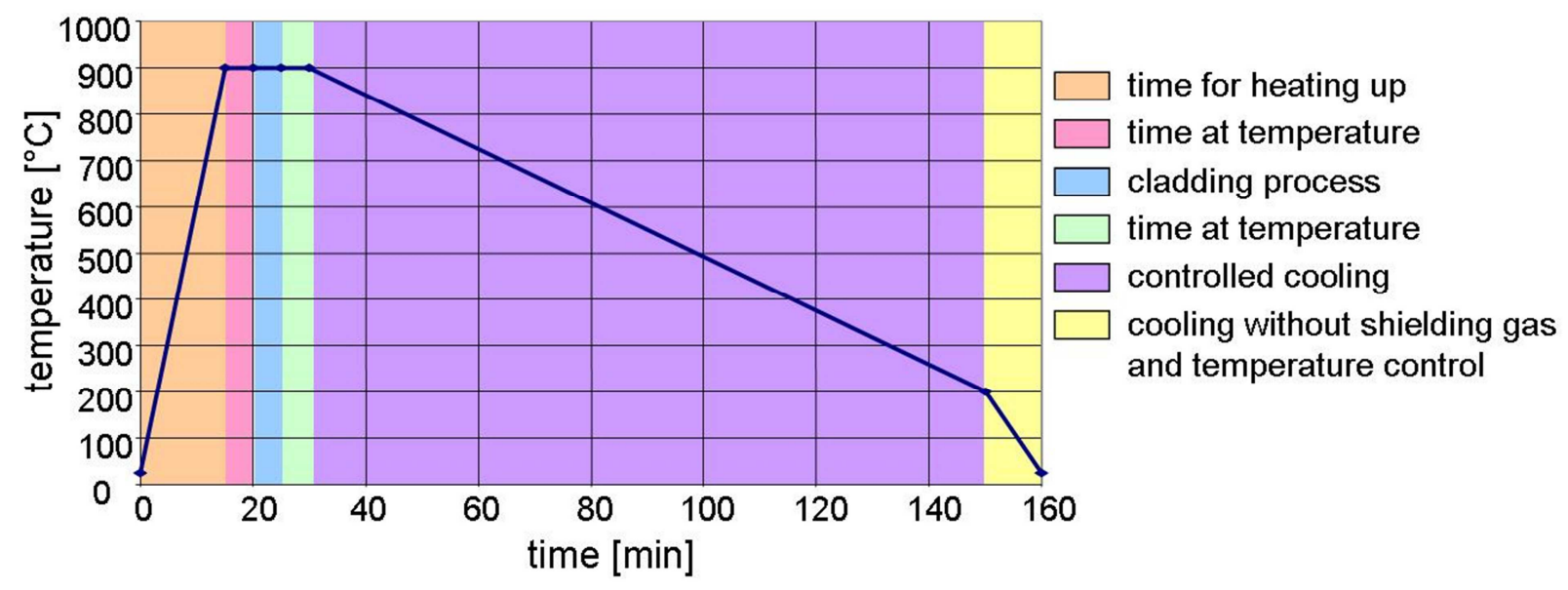

Figure 4: Thermal cycle of preheating, holding time and cooling for the cladding of TiAl 


\section{Results}

Microstructure. Defect free layers with a maximum content of $10 \mathrm{wt} .-\%$ of silicon are produced by a used laser power of $580 \mathrm{~W}$ and a feed rate of $300 \mathrm{~mm} / \mathrm{min}$ (fig. 5a). With a higher laser power of $740 \mathrm{~W}$ and a higher feed rate of $450 \mathrm{~mm} / \mathrm{min}$ defect free layers with a content of $50 \mathrm{wt} .-\%$ of titanium diboride are produced (fig. 5b). Higher contents of both additional materials lead to cracks or porosity in the cladded layers.
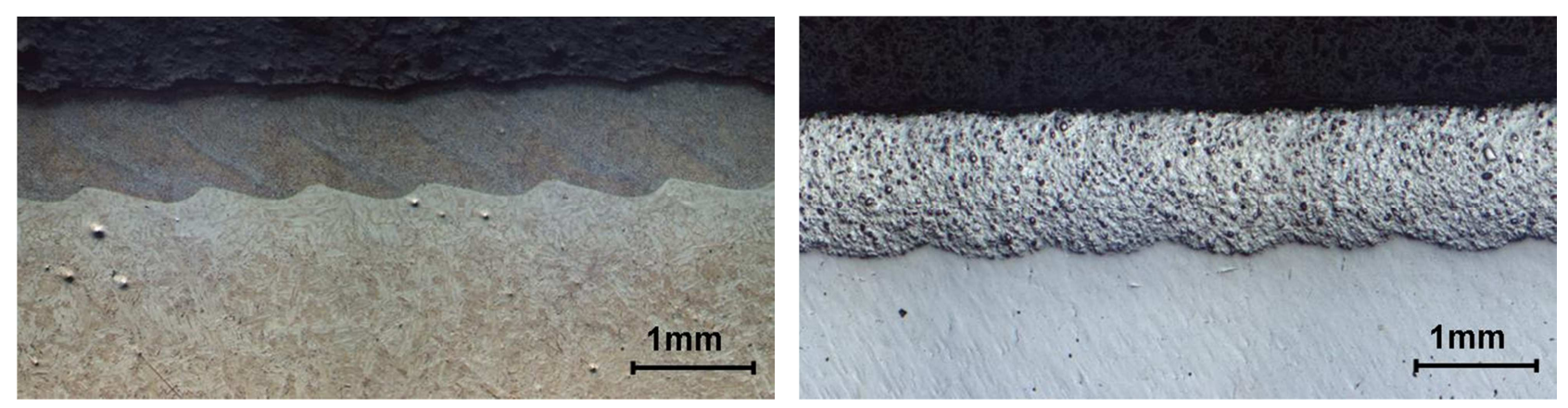

Figure 5: a: Cladded layer TiAl with 10\% Si; b: Cladded layer TiAl with 50\% $\mathrm{TiB}_{2}$

With more than 5 wt.- $\%$ of silicon the hexagonal phase $\mathrm{Ti}_{5} \mathrm{Si}_{3}$ primary solidifies from the melt. The matrix consists of the eutectic $\mathrm{TiAl}+\mathrm{Ti}_{5} \mathrm{Si}_{3}$ (fig. 6a). The quantity of primary precipitated $\mathrm{Ti}_{5} \mathrm{Si}_{3}$ in the matrix increases with increasing content of silicon. Caused by the high melting point of $\mathrm{Ti}_{5} \mathrm{Si}_{3}$ $\left(2130^{\circ} \mathrm{C}\right)$ the precipitations solidify in front of the liquid/solid interface acting as nuclei for the solidification of TiAl phases which leads to an equiaxed microstructure. The hardness increases to $500-570$ HV0.3 in comparison to the base material with a hardness of 370 HV0.3. Fig. 6b shows an SEM photograph of the $\mathrm{TiAl}+\mathrm{TiB}_{2}$ microstructure. The $\mathrm{TiB}_{2}$ particles are almost completely preserved. Some melting occurs followed by a dendritic solidification of $\mathrm{TiB}_{2}$ in the matrix.
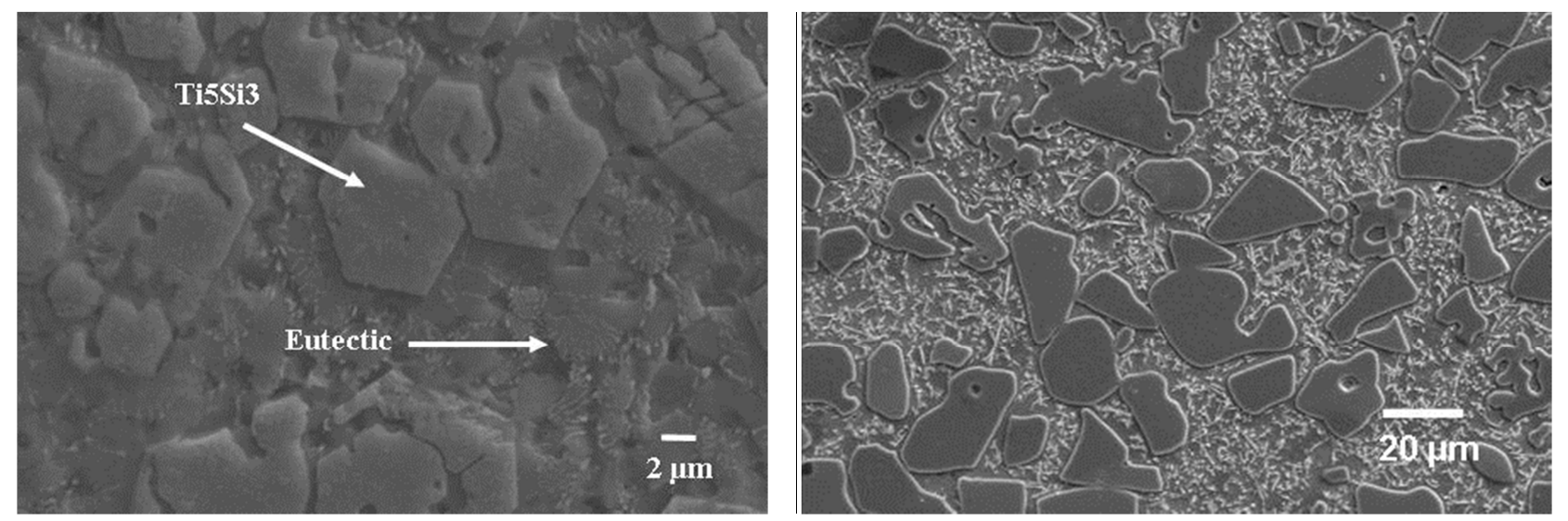

Figure 6: a: Microstructure TiAl with 10 wt.-\% Si; b: Microstructure TiAl with 50 wt.-\% TiB 2

Wear resistance tests. The abrasive wear resistance of the cladded layers in comparison to the base material is shown in figure 7. Two samples are tested for each material. The difference between sample 1 and 2 is due to a different adjustment of the air pressure and not related to the microstructure. A significant decrease of $60 \%$ of abrasive wear can be achieved by adding 50 wt.- $\%$ titanium diboride particles. This increase of wear resistance is caused by the high hardness of the $\mathrm{TiB}_{2}$ particles and their high bonding strength in the TiAl matrix. A content of $10 \mathrm{wt}-\%$ silicon has no significant influence on the wear resistance. In comparison to the hardness of $\mathrm{TiB}_{2}$ (approx. 25.6 Knoop) the phase $\mathrm{Ti}_{5} \mathrm{Si}_{3}$ has a low hardness (approx. $12 \mathrm{Knoop}$ ). Si additions are therefore not suitable for pure abrasive wear. 


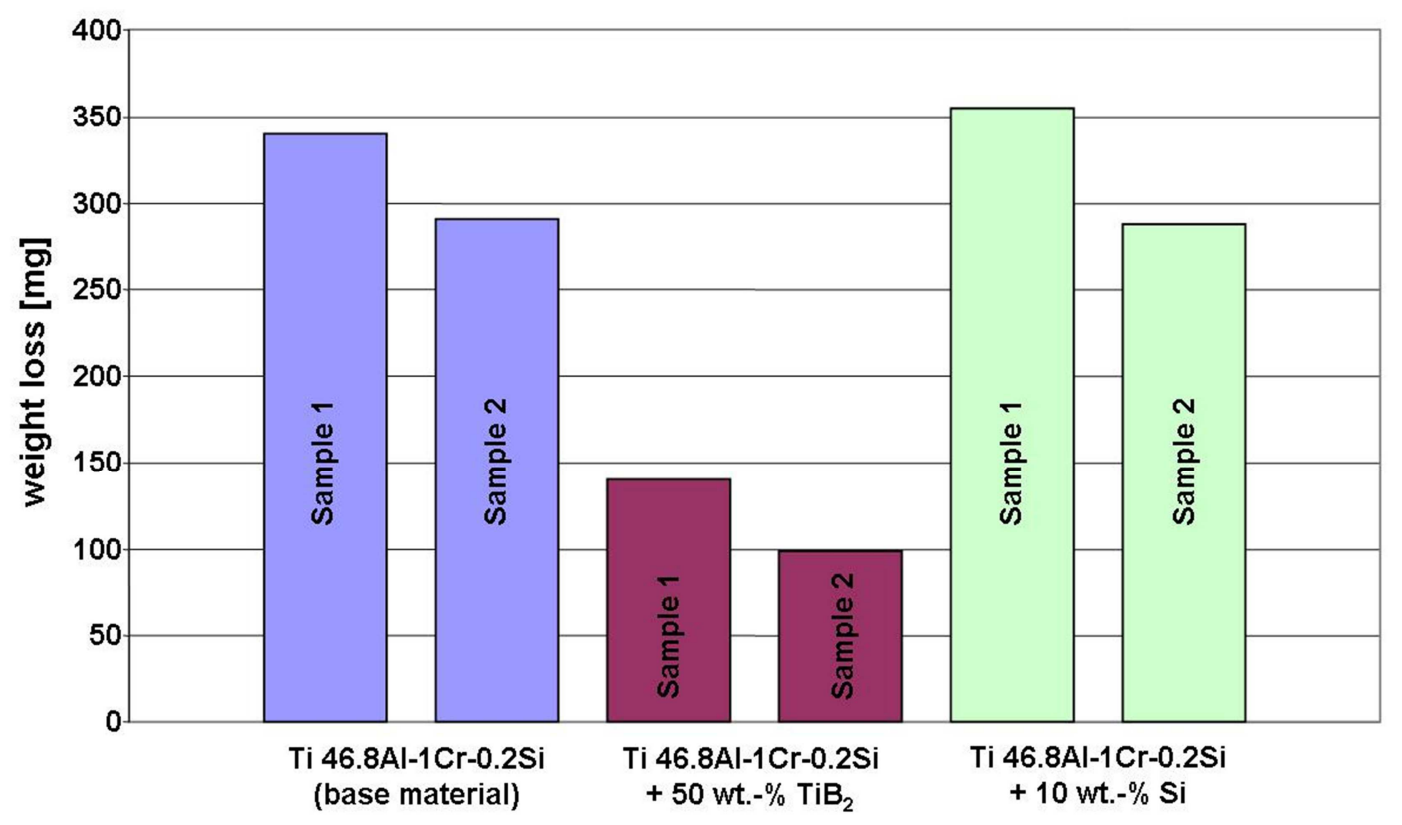

Figure 7: Comparison of abrasive wear resistance of cladded material and base material

Oxidation resistance tests. The samples are heated up to 800 degrees Celsius in air for 96 hours. After every 24 hours the samples are weighed to measure the oxidation rate. The results are shown in figure 8 . In the first 24 hours the base material and the cladded sample with an addition of 50 wt.$\% \mathrm{TiB}_{2}$ show a higher oxidation rate compared to the cladded sample with addition of $10 \mathrm{wt} .-\%$ silicon. Silicon in titanium aluminide alloys inhibits the oxidation. If the thickness of the oxidized material reaches a certain threshold the rate of oxidation is determined by the rate of diffusion through the oxide layer. This explains the constant increase of the oxidation rate of all samples after a time of more than 48 hours.

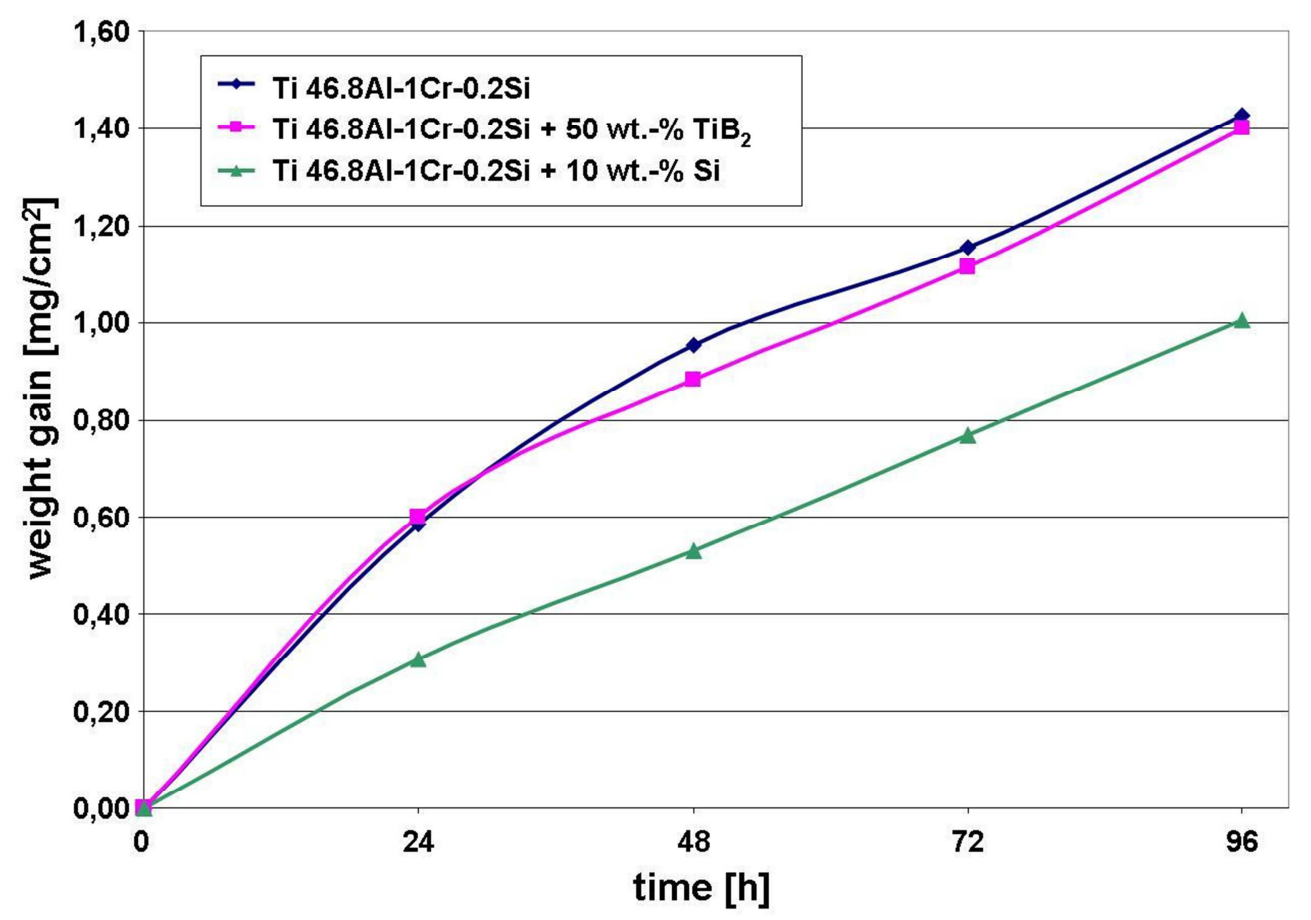

Figure 8: Comparison of oxidation behavior of cladded material and base material at $800^{\circ} \mathrm{C}$ in air 


\section{Conclusions and outlook}

Experimental investigations show that laser cladding is a process, which can be used for wear and oxidation protection of titanium aluminide materials. Cladded layers of Ti-46.8Al-1Cr-0.2Si modified with additions of silicon or titanium diboride are produced without cracks by preheating up to temperatures of 900 degrees Celsius. With contents of $10 \mathrm{wt} .-\%$ silicon the growth of the oxide layer at a temperature of 800 degrees Celsius can be decreased significantly. The abrasive wear of a cladded layer with $50 \mathrm{wt} .-\%$ titanium diboride is $60 \%$ less in comparison to the base material.

The results of this work show the potential of laser cladding with tailored layers for future applications such as wear and corrosion resistance of titanium aluminides (e.g. turbine blades, components of combustion engines). Further investigations on real parts and tests under service conditions are needed to bring this technology into industrial practice.

\section{Acknowledgement}

The authors like to thank the DFG for the funding of this work (WE 1821/8-1 and KE 1540/1-2)

\section{References}

[1] Peters, M.; Leyens, C.: Titan und Titanlegierungen, DMG Wiley- VCH Verlag GmbH \& Co.KG, Weinheim, 2002

[2] Clemens, H., Kestler, H.; Processing and Applications of Intermetallic $\gamma$-TiAl-Based Alloys, Advanced Eng. Mat. 2, No. 9 (2000) 551-571

[3] Knippscheer, S.; Frommeyer, G.: Intermetallic TiAl (Cr, Mo, Si) Alloys for Lightweight Engine Parts, Advanced Engineering Materials 1999, 1, No. 3-4

[4] Threadgill, P. L.: The prospects for joining titanium aluminides, Materials Science and Engineering A192/193, 1995

[5] Smarsly, W.; Triebwerkstoffe - “Quo Vadis”, DLR Kolloquium, MTU Engines GmbH, 2002

[6] Weisheit, A., Korrosions- und Verschleißschutz von Gamma-TiAl-Legierungen durch Laserstrahl-Auftragschweißen artähnlicher Werkstoffe, DFG-Antrag WE1821/8-2, Lehrstuhl für Lasertechnik, RWTH Aachen, 2003

[7] Weisheit, A.; Backes, G.; Stromeyer, R.; Gasser, A.; Wissenbach, K.; Poprawe, R.: Powder Injection: The Key to Reconditioning and Generating Components Using Laser Cladding, Proceedings of Materials Week, 2001 